\title{
The Defensive Role of Volatile Emission and Extrafloral Nectar Secretion for Lima Bean in Nature
}

\author{
Christian Kost • Martin Heil
}

Received: 9 August 2007 / Revised: 3 November 2007 / Accepted: 14 November 2007 / Published online: 12 December 2007

(C) Springer Science+Business Media, LLC 2007

\begin{abstract}
Lima bean (Phaseolus lunatus) features two indirect anti-herbivore defenses - emission of volatile organic compounds (VOCs) and secretion of extrafloral nectar (EFN) - which are both inducible upon herbivore damage. In a previous field study, Lima bean benefited from the simultaneous induction of the two defenses, yet it remained unclear whether both had contributed to plant protection. Our experimental approach aimed at studying the defensive role of both indirect defenses simultaneously. Tendrils were sprayed with jasmonic acid (JA) to induce both defenses, and performance was compared to that of others that were treated with a synthetic blend of either EFN or VOCs. Confirming earlier results, JA treatment and application of the VOC mixture induced EFN secretion in treated tendrils in quantitatively similar amounts. The
\end{abstract}

Electronic supplementary material The online version of this article doi:10.1007/s10886-007-9404-0 contains supplementary material, which is available to authorized users.

\section{Kost $\cdot$ M. Heil}

Department of Bioorganic Chemistry, Max Planck Institute for

Chemical Ecology, Beutenberg Campus, Hans-Knöll-Str. 8,

07745 Jena, Germany

Present address:

C. Kost $(\square)$

Evolutionary Genetics and Microbial Ecology Laboratory,

New Zealand Institute for Advanced Study, Massey University,

Private Bag 102 904, North Shore Mail Centre,

Auckland, New Zealand

e-mail: christiankost@web.de

Present address:

M. Heil

Departamento de Ingeniería Genética, CINVESTAV-Irapuato, Km. 9.6 Libramiento Norte, Irapuato,

Guanajuato CP 36821, Mexico composition of the applied synthetic blend of EFN was adjusted to match the concentration of EFN secreted from JA- and VOC-treated tendrils. Repeated application of either enhanced the performance of several fitness-relevant plant parameters such as growth rate and flower production. Tendrils treated with JA showed a similar trend, yet some fitness-related parameters responded less to this treatment. This suggests a minor importance of any putative JAdependent direct defense traits or higher costs of JA-elicited responses as compared to VOCS and EFN, as otherwise JA-treated tendrils should have outperformed VOC- and EFN-treated tendrils. Moreover, the beneficial effect of applying synthetic EFN alone equaled or exceeded that of VOCs and JA. Ants were by far the dominant group among the arthropods that was attracted to JA-, VOC-, or EFNtreated tendrils. The results suggest that EFN plays a more important role as an indirect defense of lima bean than VOCs or any other JA-responsive trait.

Keywords Ants · Extrafloral nectar · Indirect defense ·

Phaseolus lunatus . Plant-plant communication.

Volatile organic compounds

\section{Introduction}

Plants respond to herbivore attack with an array of changes in plant chemistry, morphology, and physiology, which frequently result in the increased resistance of plants to further attack (Karban and Baldwin 1997). Induced resistance may be caused by direct effects on the herbivore through plant-derived toxic metabolites or anti-digestive and anti-nutritive compounds. Furthermore, plants may utilize indirect defenses that facilitate top-down control of 
herbivore populations by the herbivore's predators and parasitoids (Price et al. 1980).

One way a plant may attract beneficial arthropods is by providing suitable food sources such as extrafloral nectar (EFN; Koptur 1992). EFN is an aqueous solution, with sugars and amino acids being the most abundant solutes (Ruffner and Clark 1986; Galetto and Bernardello 1992; Heil et al. 2000), which is secreted from specialized organs, the extrafloral nectaries. In addition, plants may increase the emission rate of volatile organic compounds (VOCs) in response to herbivore attack. VOCs can serve as a cue that guides foraging parasitoids and predators to the feeding herbivore (Turlings et al. 1990; Paré and Tumlinson 1997). The composition of the herbivore-induced volatile blend depends not only on the plant species or cultivar but also varies with the species and even the larval stage of the herbivore (for review, see Arimura et al. 2005), thus providing highly reliable signals to the members of the third trophic level.

In many cases, plants do not rely on a single defense strategy but employ a complex array of different defensive mechanisms. For example, several plant species feature both VOC emission and EFN secretion (Arimura et al. 2005). The presence of two indirect defenses within one individual plant gives rise to the questions whether both defenses contribute to plant fitness and how they interact in attracting beneficial arthropods (Price et al. 1980). Studies on the benefit of indirect defense traits in nature are generally rare (but see Thaler 1999 and Kessler and Baldwin 2001). No study to date has tried to study the defensive roles of two indirect defenses within one plant species simultaneously.

The lima bean (Phaseolus lunatus) is a common model system in studies on induced indirect defenses. Heil (2004b) showed that plants growing in the wild, which had been induced by exogenous application of the phytohormone jasmonic acid (JA), responded by increasing both their VOC emission and EFN secretion. The application of JA repeatedly (i.e., every 3 days) resulted in benefits for the treated plants as reflected by a decreased herbivory rate and an increased seed set. However, JA also affects fitness-relevant processes such as fruit development and ripening (Creelman and Mullet 1997). Thus, the multiple effects constrain the interpretation of the observed morphological changes as being exclusively attributable to induced defenses. Furthermore, Kost and Heil (2005) demonstrated that an artificial increase of the amount of available EFN benefits lima bean in nature by attracting predacious and parasitoid arthropods. These two pilot studies represented a starting point for unraveling whether both induced defense traits contribute to plant defense or whether EFN secretion solely is responsible for lima bean protection.

We chose an experimental approach similar to the one used in Heil (2004b): Groups of five tendrils were used as

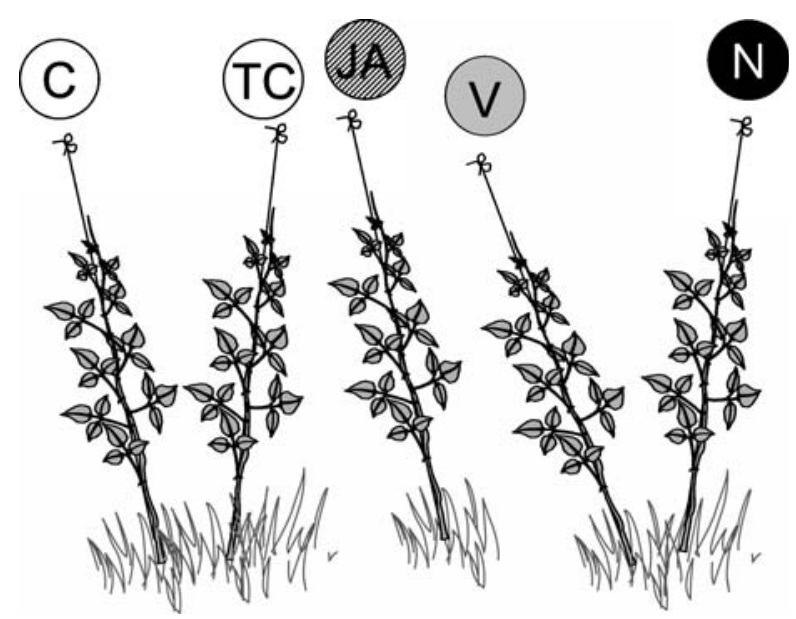

Fig. 1 Experimental design. Five groups of lima bean tendrils $(P$. lunatus) served as experimental unit with $C$ no treatment, TC application of lanolin paste, $J A$ spraying with jasmonic acid, $V$ application of a synthetic volatile blend dissolved in lanolin paste, and $N$ application of a synthetic mixture of EFN. See Table 1 for details

experimental units (Fig. 1; Table 1). Within each unit, two tendrils were either treated with JA or left untreated. The inclusion of two additional bean tendrils with artificially increased amounts of either VOCs or EFN enabled us to study the protective effect of the two defenses. A fifth group served as a treatment control.

We repeatedly applied these five treatments to address the following questions: (1) What is the relative contribution of the two indirect defenses - volatile emission and extrafloral nectar secretion - to the overall herbivore defense of the lima bean? (2) Is there an additional influence of a putative JA-dependent direct defense? And (3) what kind of arthropods (including putative defenders) are attracted to the treated tendrils?

\section{Methods and Materials}

Study Site and Species This study was conducted in the coastal area near Puerto Escondido in the state of Oaxaca, Mexico. The climate in the study area is characterized by one main rainy season from June to October, which follows a bimodal distribution peaking in July and September. Annual rainfall averages between 1 and $1.4 \mathrm{~m}$, and the mean annual temperature is $28^{\circ} \mathrm{C}$ (Strässne 1999). The two sites were used in previous studies (Heil 2004b; Kost and Heil 2005) and located $15 \mathrm{~km}$ northwest of Puerto Escondido and about $3 \mathrm{~km}$ apart $\left(15^{\circ} 55.596 \mathrm{~N} / 097^{\circ}\right.$ $09.118 \mathrm{~W}$ and $15^{\circ} 55.357 \mathrm{~N} / 97^{\circ} 08.336 \mathrm{~W}$ ). In this study, lima bean grows naturally along dirt roads that lead to extensively used pastures or plantations. All experiments were performed on this native population of lima bean plants in 2003 and 2004, during the transition from wet to dry season (October to December). 
Table 1 Five chemical treatments and their effect on treated tendrils

\begin{tabular}{|c|c|c|c|}
\hline Group Name (Abbreviation) & Treatment & $\begin{array}{l}\text { Defensive Traits }(i=\text { Induced, } \\
e=\text { Experimentally Increased })\end{array}$ & Effect \\
\hline Control (C) & Untreated & None & Untreated control \\
\hline Treatment control (TC) & Lanolin paste & None & Lanolin paste only \\
\hline JA-treatment (JA) & JA & $\begin{array}{l}\text { VOCs (i) EFN (i) } \\
\text { putative direct resistance (i) }\end{array}$ & $\begin{array}{l}\text { Induction of VOCs, EFN, } \\
\text { and putative JA-dependent } \\
\text { direct defenses (Heil 2004b) }\end{array}$ \\
\hline Volatile treatment $(\mathrm{V})$ & $\begin{array}{l}\text { Volatile mixture dissolved } \\
\text { in lanolin paste }\end{array}$ & VOCs (e) EFN (i) & $\begin{array}{l}\text { Induction of EFN, attraction } \\
\text { of arthropods to VOCs and EFN } \\
\text { (Kost and Heil 2006) }\end{array}$ \\
\hline Nectar treatment $(\mathrm{N})$ & Synthetic mixture of EFN & EFN (e) & $\begin{array}{l}\text { Attraction of arthropods to EFN } \\
\text { (Kost and Heil 2005) }\end{array}$ \\
\hline
\end{tabular}

$J A$ Jasmonic acid, EFN extrafloral nectar, $V O C$ volatile organic compound

Design of the Long-Term Experiment To reduce environmental and genotypic variability, 23 groups of five lima bean tendrils were selected as experimental units. Within a unit, the maximum distance between the two outer tendrils was less than $3 \mathrm{~m}$, and tendrils forming one group usually were part of the same plant individual, although this could not always be ensured because of the tangled growth of the lima bean. Eleven groups were located at site 1 and 12 at site 2. All selected tendrils were trained along supporting ropes, and the tendrils of each group assigned randomly to one of five treatments (for details, see the next section): Tendrils were either left untreated (control group) or treated every 3-4 days with lanolin paste only (treatment control group), sprayed with an aqueous solution of JA (JA group), or supplied with a synthetic blend of VOCs (volatile group) or EFN (EFN group; Fig. 1; Table 1). Application of pure lanolin served as a procedural control to test for any effect caused by lanolin alone. See Table 1 for a summary of the expected treatment effects. Starting 27th October 2003, the experiment lasted 25 days and comprised six applications. During this time, the initial number of tendril groups was reduced to a final sample size of 17 because of cattle and human impact.

Treatment of Tendril Groups Tendrils of the JA group were sprayed with an aqueous solution of $1 \mathrm{mmol} \mathrm{JA}$ until runoff (i.e., approximately $10 \mu \mathrm{l}$ per $\mathrm{cm}^{2}$ leaf area). Levels of JA were adjusted to those of previous experiments in which similar concentrations were applied without phytotoxic effects becoming apparent (Heil 2004b). The synthetic volatile blend and the synthetic mixture of EFN were adjusted to mimic their natural models within 3 days postinduction according to previous experiments (Kost and Heil 2005, 2006). However, the amount of VOCs and EFN cumulatively applied ranged largely below the physiological limit of a plant for producing the two indirect defenses within this period (Kost and Heil 2005, 2006).
The synthetic volatile blend consisted of $0.12 \mu \mathrm{g}(R)-(-)-$ linalool, $0.13 \mu \mathrm{g} \beta$-caryophyllene, $0.19 \mu \mathrm{g}$ methyl salicylate, $0.26 \mu \mathrm{g}(Z)$-jasmone (all purchased from Sigma-Aldrich), $0.02 \mu \mathrm{g}$ (3Z)-hexen-1-yl acetate (Avocado Research Chemicals Ltd., Leysham, Lancaster, UK), $0.85 \mu \mathrm{g}(E, Z)-\beta-$ ocimene (mixture of $E / Z$-isomers approximately 70:30; kindly provided by Roger Snowden, Firmenich, Geneva, Switzerland), $0.63 \mu \mathrm{g}$ (3E)-4,8-dimethyl-nona-1,3,7-triene (DMNT), and $0.9 \mu \mathrm{g}(3 E, 7 E)-4,8,12$-trimethyltrideca1,3,7,11-tetraene (TMTT; synthesized by standard methods; Pattenden and Weedon 1968) per microliter lanolin. The purity of all compounds was $>98 \%$. Pure lanolin and lanolin paste that contained volatiles were spotted on green plastic strips attached to tendrils to prevent any diffusion of compounds into the treated plant. A total of $120 \mu \mathrm{l}$ of paste were applied per five leaves of either the volatile- or the treatment-control group.

The synthetic EFN consisted of an aqueous solution of $4.01 \mathrm{~g} \mathrm{l}^{-1}$ sucrose and $24.24 \mathrm{~g} \mathrm{l}^{-1}$ of each fructose and glucose. Of this blend, $40 \mu \mathrm{l}$ were applied with an Eppendorf pipette directly to the extrafloral nectaries of every trifoliate leaf of the EFN group.

Comparison of Treatments To ensure comparability between experimental groups of the long-term experiment, we quantified VOC and EFN levels of differently treated tendrils in preceding experiments.

The ability of our VOC mixture to mimic the volatile emission of herbivore-damaged and JA-induced tendrils was examined by quantifying the VOCs present in the headspace of tendrils that had received one of five treatments. Tendrils were either left untreated or treated with lanolin paste, infested for $48 \mathrm{~h}$ with a representative mixture of natural herbivores of lima bean (six Ensifera or Caelifera and ten beetles of various species, i.e., Cerotoma ruficornis, Gynandrobrotica guerreroensis, Epilachna var- 
ivestis, and a curculionid species; for details, see Kost and Heil 2006), treated with a blend of synthetic VOCs, or sprayed with a 1-mmol aqueous solution of JA. Each treatment was replicated six to eight times. Groups of five tendrils that had received the different treatments originated from plants that were spaced apart at a maximum distance of approximately $3 \mathrm{~m}$, had five leaves, matched each other in terms of leaf age and visual appearance, and were collected at the same time for simultaneous volatile collection. Treated tendrils were detached, immediately supplied with a water reservoir, and bagged in a PET foil ('Bratenschlauch', Toppits, Minden, Germany) that does not emit detectable amounts of volatiles by itself. Emitted VOCs were collected continuously on charcoal traps (1.5 mg charcoal, CLSA Filters, Le Ruisseau de Montbrun, France) by using air circulation, as described by Donath and Boland (1995). After $24 \mathrm{~h}$, volatiles were eluted from the carbon trap with dichloromethane $(40 \mu \mathrm{l})$ that contained 1-bromodecane $\left(200 \mathrm{ng} \mathrm{\mu l}^{-1}\right)$ as an internal standard. Samples were transferred to glass capillaries, sealed by melting the open end, and stored at $<5^{\circ} \mathrm{C}$ for transport. Samples were analyzed on a gas chromatography-trace mass spectrometer (Thermo Finnigan, http://www.thermofinnigan. com) according to Koch et al. (1999). Individual compounds (peak areas) were quantified with respect to the peak area of the internal standard.

To compare quantitatively the amount of EFN secreted from tendrils after exposure to airborne VOCs or induction with JA, 11 groups of three tendrils spread across the two sites were selected; these groups were located $<1 \mathrm{~m}$ apart. Each tendril was basifixed and had five leaves. The first tendril within each group was treated with lanolin paste, the second with lanolin paste that contained volatiles, and the third was sprayed with JA. All treatments were similar to those described above. The three tendrils were then placed in gauze bags (mesh size, $0.5 \mathrm{~mm}$ ), and a ring of sticky resin (Tangletrap ${ }^{\circledR}$, Tanglefoot Company, Grand Rapids, MI, USA) was applied at the base as protection against flying and crawling nectar consumers. After $24 \mathrm{~h}$, the amount of newly produced EFN was measured as the amount of secreted soluble solids (i.e., sugars, amino acids; see Heil et al. 2000) by quantifying the nectar volume with micro-capillaries and the nectar concentration with a portable, temperature-compensated refractometer (Heil et al. 2000, 2001). Both the amount of VOCs emitted and EFN secreted were referenced to the dry weight of the measured tendrils.

Fitness-Relevant Plant Parameters To assess the effect of treatments on the fitness of the study tendrils, the following fitness-relevant plant parameters were considered: number of leaves, inflorescences, living and dead shoot tips, and herbivory rate. Herbivory rate was estimated as percent leaf loss, as described in Kost and Heil (2005), and the remaining parameters were quantified by counting. All five parameters were assessed at the beginning of the experiment and after 25 days. Differences between these two values were calculated to determine the development of the respective parameter in the course of the study period.

Insect Counts and Sticky Traps The insect community that visited the treated bean tendrils was assessed by counting and with sticky traps. Two series of insect countings were performed, in which 20 tendril groups of the long-term experiment located at both sites were visited repeatedly. The first series of countings started on day 7 and the second on day 18 after the onset of the experiment. Ten groups of tendrils were selected at each study site, and the number of ants, wasps, or flies present on the plants was recorded, as these insects represented the most abundant groups. The first census was performed before tendril treatment at 8:00 A.M. Thereafter, all tendrils were treated, and insects on all experimental tendrils were counted repeatedly every 2 or $3 \mathrm{~h}$ until midnight. Two additional censuses were performed at 9:00 and 10:00 A.M. on the following 2 days, resulting in a total of 14 monitorings. The number of all insects counted per tendril was summed up to test for an effect of the treatment on the total number of insects observed.

To assess the functional groups of insects attracted to the experimental tendrils, two sticky traps were attached with plastic strings to each tendril of 14 groups that were equally distributed between the study sites. The sticky traps consisted of $100 \mathrm{~cm}^{2}$ pieces of green plastic foil that had been coated with a thin layer of a trapping adhesive (Tangletrap ${ }^{\circledR}$ ). After $24 \mathrm{~h}$ of exposure, traps were collected and the insects transferred to $75 \%$ ethanol. Insects were identified to order or family level with keys and information provided by Arnett (2000), Schaefer et al. (1994), and Noyes (2003). On the basis of the natural history information provided by Kelsey $(1969,1981)$, Honomichl et al. (1996), Matile (1997), and Daly et al. (1998), the collected arthropods were assigned to the following guilds according to nutritional or functional aspects: Predator/ entomophaga $(\mathrm{R})$, parasitoid $(\mathrm{P})$, utilization of plant-derived resources including floral or extrafloral nectar, pollen and honeydew (S), frugivore $(\mathrm{F})$, herbivore and flower feeder $(\mathrm{H})$, detrivore including phytosaprophage and zoosaprophage (D), blood-sucking and ectoparasitic (B), and fungivore (M).

Statistical Analysis Amounts of volatiles emitted from differentially treated tendrils were compared with a Kruskal-Wallis rank sum test and a subsequent nonparametrical multiple test procedure of the Behrens-Fisher type (Munzel 
and Hothorn 2001) by using the open source software $\mathrm{R}$ 2.3.1 (http://www.r-project.org).

Our randomized complete block design allowed us to analyze the data of the EFN-induction experiment, the fitness-relevant plant parameters, and the cumulative insect numbers with a mixed-effect model (univariate GLM procedure) with 'treatment' as a fixed and 'tendril group' as a random factor. The following variables were transformed to meet the assumption of homogeneity of variances (transformation in brackets): number of living shot tips and number of wasps (square root), number of inflorescences and dead shoot tips (log), number of leaves, cumulative number of ants and flies (ln). Post hoc comparisons (least significant difference, LSD) were performed to test for statistically significant differences among treatments. These statistical analyses were done using Statistical Package for the Social Sciences 13.0 (SPSS Inc., Chicago, USA).

\section{Results}

Comparison of Treatments The headspace of lima bean tendrils, which had been treated with either a blend of synthetic VOCs or with JA, largely resembled the volatile blend typically emitted from herbivore-damaged bean tendrils in terms of quantity and quality (Table 2). Only (3Z)-hexen-1-yl acetate was emitted in significantly lower amounts from the synthetic VOC mixture than from herbivore-induced tendrils. Also, JA- and herbivore-treated tendrils showed a marked quantitative similarity in the composition of their emitted volatile bouquets. However,
JA-treated tendrils emitted significantly lower amounts of $(R)-(-)$-linalool and higher amounts of DMNT compared to herbivore-damaged tendrils. In general, volatile blends emitted from herbivore-, volatile-, and JA-treated plants were characterized by high quantitative variability (Table 2).

A similar trend became obvious when EFN secretion rates were compared among treatments. Both the application of the synthetic volatile mixture and the JA treatment increased the EFN secretion rate within $24 \mathrm{~h}$ compared to controls treated with lanolin only (univariate analysis of variance, ANOVA, $P<0.01, N=11)$. The EFN secretion rate in both treatments was twice that of the treatment control (Fig. 2). However, no significant difference was detected between the volatile- and the JA-treated group (LSD post hoc test, $P>0.05$ ).

Effect of the Treatments on Fitness-Relevant Plant Parameters The three treatments, JA, volatiles, and EFN, significantly affected vegetative and reproductive plant traits after 25 days as compared to the controls. Tendril groups treated with volatiles or EFN showed a significant increase in the number of newly produced leaves, shoot tips, and inflorescences, bore fewer dead shoot tips, and had suffered less herbivore damage than the controls (Fig. 3). JA treatment also significantly decreased the number of dead shoot tips and the herbivory rate, whereas no difference could be detected for the number of living shoot tips, leaves, and inflorescences. According to a LSD post hoc test, the tendrils of the JA group ranked between the volatile and EFN group on one hand and the two controls on the other (Fig. 3).

Table 2 Quantitative comparison of five-leaved lima bean tendrils, which were left untreated (C); treated with lanolin paste (Tc); exposed to a mixture of herbivores, which are characteristic for the lima bean for $48 \mathrm{~h}(\mathrm{H})$; treated with the artificial volatile blend dissolved in lanolin paste (V); or sprayed with JA

\begin{tabular}{|c|c|c|c|c|c|c|}
\hline \multirow[t]{2}{*}{ Compound } & \multicolumn{6}{|c|}{ Emission $\left(A_{\mathrm{VOC}} A_{\mathrm{IS}}^{-1} \mathrm{~g}^{-1} 24 \mathrm{~h}^{-1}\right)$} \\
\hline & $\mathrm{C}(N=8)$ & $\mathrm{TC}(N=7)$ & $\mathrm{H}(N=6)$ & $\operatorname{VOCs}(N=7)$ & JA $(N=7)$ & $\mathrm{KW}$ test \\
\hline (3Z)-Hexen-1-yl acetate & $0.03 \pm 0.03^{\mathrm{a}}$ & $0.01 \pm 0.01^{\mathrm{a}}$ & $0.15 \pm 0.21^{\mathrm{a}}$ & $0.03 \pm 0.06^{\mathrm{b}}$ & $0.34 \pm 0.35^{\mathrm{a}}$ & $=0.07$ \\
\hline$(Z)-\beta$-Ocimene & $0.00 \pm 0.00^{\mathrm{a}}$ & $0.00 \pm 0.00^{\mathrm{a}}$ & $0.03 \pm 0.05^{\mathrm{ac}}$ & $0.13 \pm 0.10^{\mathrm{bc}}$ & $0.07 \pm 0.12^{\mathrm{ac}}$ & $<0.001$ \\
\hline (E)- $\beta$-Ocimene & $0.01 \pm 0.01^{\mathrm{a}}$ & $0.02 \pm 0.04^{\mathrm{a}}$ & $0.42 \pm 0.64^{\mathrm{bc}}$ & $0.23 \pm 0.19^{\mathrm{bc}}$ & $0.86 \pm 1.60^{\mathrm{ac}}$ & $<0.01$ \\
\hline (R)-(-)-Linalool & $0.05 \pm 0.07^{\mathrm{a}}$ & $0.06 \pm 0.06^{\mathrm{a}}$ & $0.64 \pm 0.55^{\mathrm{b}}$ & $0.39 \pm 0.41^{\mathrm{b}}$ & $0.06 \pm 0.09^{\mathrm{a}}$ & $<0.01$ \\
\hline DMNT & $0.04 \pm 0.05^{\mathrm{a}}$ & $0.07 \pm 0.07^{\mathrm{a}}$ & $0.76 \pm 0.91^{\mathrm{b}}$ & $1.18 \pm 0.86^{\mathrm{bc}}$ & $0.96 \pm 1.56^{\mathrm{ac}}$ & $<0.001$ \\
\hline $\mathrm{C}_{10} \mathrm{H}_{14}$ & $0.03 \pm 0.06^{\mathrm{a}}$ & $0.18 \pm 0.22^{\mathrm{a}}$ & $1.43 \pm 0.81^{\mathrm{bc}}$ & $1.16 \pm 0.97^{\mathrm{bc}}$ & $0.32 \pm 0.42^{\mathrm{ac}}$ & $<0.001$ \\
\hline Methyl salicylate & $0.02 \pm 0.02^{\mathrm{a}}$ & $0.13 \pm 0.10^{\mathrm{ac}}$ & $0.34 \pm 0.31^{\mathrm{ad}}$ & $0.78 \pm 0.58^{\mathrm{bcd}}$ & $0.07 \pm 0.12^{\mathrm{a}}$ & $<0.01$ \\
\hline $\mathrm{C}_{10} \mathrm{H}_{16} \mathrm{O}$ & $0.08 \pm 0.11^{\mathrm{a}}$ & $0.15 \pm 0.28^{\mathrm{a}}$ & $0.45 \pm 1.01^{\mathrm{a}}$ & $0.45 \pm 0.67^{\mathrm{a}}$ & $0.68 \pm 1.03^{\mathrm{a}}$ & $=0.64$ \\
\hline (Z)-Jasmone & $0.01 \pm 0.02^{\mathrm{ac}}$ & $0.00 \pm 0.00^{\mathrm{a}}$ & $0.21 \pm 0.22^{\mathrm{bd}}$ & $1.21 \pm 1.21^{\mathrm{be}}$ & $0.35 \pm 0.44^{\text {cde }}$ & $<0.01$ \\
\hline$\beta$-Caryophyllene & $0.01 \pm 0.01^{\mathrm{a}}$ & $0.03 \pm 0.05^{\mathrm{a}}$ & $1.23 \pm 2.10^{\mathrm{b}}$ & $0.75 \pm 0.66^{\mathrm{b}}$ & $0.26 \pm 0.28^{\mathrm{b}}$ & $<0.001$ \\
\hline TMTT & $0.02 \pm 0.02^{\mathrm{a}}$ & $0.09 \pm 0.08^{\mathrm{ac}}$ & $0.43 \pm 0.34^{\mathrm{bd}}$ & $0.85 \pm 0.71^{\text {bce }}$ & $0.69 \pm 1.21^{\text {ade }}$ & $<0.01$ \\
\hline
\end{tabular}

The dominant emitted volatiles are given as mean peak area ( $\pm 95 \%$ confidence interval) relative to the peak area of an internal standard per $24 \mathrm{~h}$ and per gram dry weight. The last column shows $P$ values of a Kruskal-Wallis $(\mathrm{KW})$ test. Significant treatment effects are indicated by different superscript letters (nonparametrical multiple test procedure of the Behrens-Fisher type, $P<0.05$ ). 


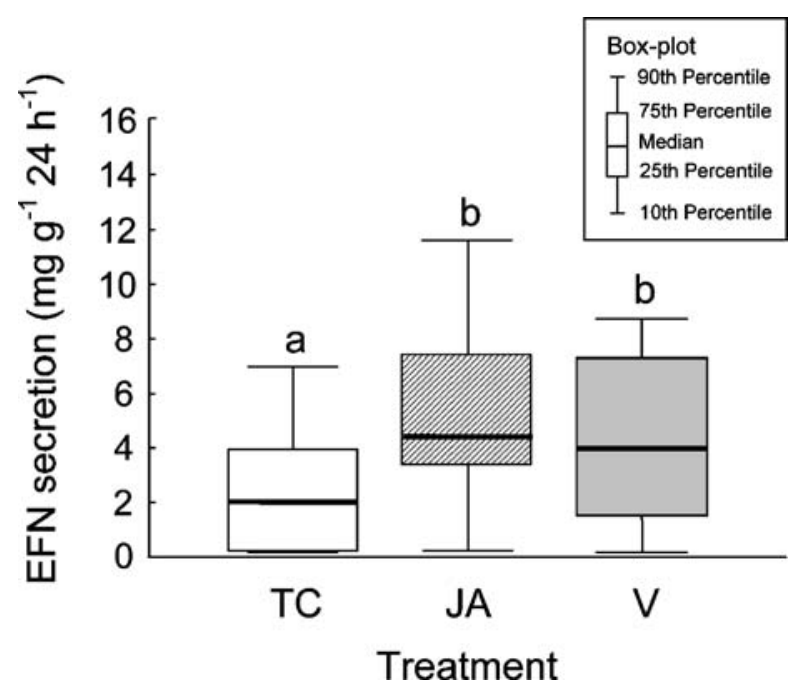

Fig. 2 Effect of different treatments on the secretion rate of extrafloral nectar $(E F N)$ given in milligrams soluble solids per gram leaf dry mass per $24 \mathrm{~h}$. Comparisons between tendrils treated with lanolin paste $(T C)$, the synthetic volatile blend dissolved in lanolin $(V)$, and jasmonic acid $(J A)$ are shown. Different letters indicate significant differences among treatments (univariate ANOVA, $P<0.05$ according to LSD post hoc test). Sample size was eleven groups of tendrils

Effect of the Treatments on Insect Abundance Ants, wasps, and flies were the most abundant groups observed visiting the study tendrils, with ants being by far the dominant group. Their numeric abundance on the experimental tendrils exceeded that of flies 5- to 15 -fold and that of wasps 20 - to 30 -fold (Fig. 4).

The five treatments significantly affected the insect visitation rate of the experimental tendrils. The mean cumulative number of ants was increased significantly on tendrils treated with JA, volatiles, and EFN relative to the two control tendrils (Fig. 4, LSD post hoc test after univariate ANOVA, $P<0.05$ ). Volatile treatment doubled the median cumulative number of ants on the experimental tendrils, whereas the JA and nectar treatment led to a threefold increase over the number on the untreated state. Correspondingly, the median wasp number ranged between 1.5 (JA group), 2 (volatile group), and 2.5 (EFN group), whereas these insects were significantly less frequently encountered on control tendrils (Fig. 4; LSD post hoc test after univariate ANOVA, $P<0.05$ ). Flies responded less to the five treatments. Despite the significantly increased visitation rate of flies to the JAtreated tendrils as compared to the controls (Fig. 4, LSD post hoc test after univariate ANOVA, $P<0.05$ ), no such effect was observed for VOC- and EFN-treated tendrils (Fig. 4). The two latter groups were statistically indistinguishable from the JA-treated tendrils and both control groups (Fig. 4, LSD post hoc test after univariate ANOVA, $P>0.05$ ).
Community Composition of Arthropods Visiting Lima Bean In total, 899 arthropods were caught on sticky traps, and $>94 \%$ were identified to the order or family level. Among them, Diptera (55\%) and Hymenoptera $(26 \%)$ were the most abundant (Table 1; Fig. 4). Other groups trapped included Coleoptera (6\%), Araneida (5\%), and Thysanoptera (3\%).

Based on information derived from the literature, the trapped arthropods were assigned to feeding guilds, whereas multiple affiliations per taxon were allowed. This analysis indicated that $73 \%$ of all trapped arthropods were characterized by parasitoid or predacious life habits and may, thus, be classified as potentially beneficial to the lima bean (Fig. 5). On the other hand, only $16 \%$ of the trapped arthropods were assigned to herbivorous or flower-feeding groups, which potentially could have had detrimental effects on the plant. Other plant-derived food sources, such as EFN, pollen, or honeydew, are known to be used by $67 \%$ of all trapped arthropod groups, and 19\% of all trapped taxa additionally rely on other food sources such as fungi, fruits, or detritus. The two latter groups may be classified as 'tourists' and are likely to have a neutral effect on the lima bean (Fig. 5; Table S1).

A closer look at the trapped arthropod taxa revealed that Dolichopodidae (34\% of all trapped Diptera), Phoridae (24\%), and Chloropidae (7\%) were the most abundantly trapped Dipterans (Table S1). All three groups share parasitoid and predacious life habits and are occasionally known to feed on EFN (Table S1). Members of the Chalcidoidea contributed preponderantly to the captured Hymenoptera $(64 \%)$. The individuals trapped by this superfamily of parasitoid wasps belonged to 16 different families, with Eulopidae (13\% of all trapped Hymenoptera), Encyrtidae (12\%), and Pteromalidae (8\%) being most frequently trapped. Among the hymenopterans, Formicidae $(12 \%)$ and Braconidae $(6 \%)$ were the most often captured non-chalcid families.

\section{Discussion}

Comparison of Treatments The aim of the present study was to study simultaneously the protective effect of the two indirect defenses, EFN secretion and VOC emission, on the lima bean under field conditions. The performance of plants that were induced by spraying with JA and, thus, had increased amounts of VOCs and EFN, was monitored and compared to plants of which the amount of either VOCs or EFN was increased experimentally.

An important prerequisite for any conclusion that can be drawn from such an experimental design is knowledge of the performance of the two indirect defenses under 
Fig. 3 Effect of five treatments on fitness-relevant plant parameters. Each tendril within groups of five lima bean tendrils received one of five treatments: no treatment $(C)$, treatment with lanolin paste $(T C)$, spraying with jasmonic acid $(J A)$, application of a synthetic volatile blend dissolved in lanolin paste $(V)$, and application of a synthetic mixture of EFN $(N)$. See Table 1 for details. Mean absolute differences between days 0 and 25 of the experiment are displayed. Values above zero (dashed line) indicate an increase and values below a decrease in comparison to the starting situation. Asterisks indicate significant treatment effects (univariate ANOVA; $* P<0.05$, $* * P<0.01, * * * P<0.001)$, and different letters indicate significant differences among treatments (LSD post hoc test, $P<$ 0.05 ). Sample size was 20 groups of tendrils
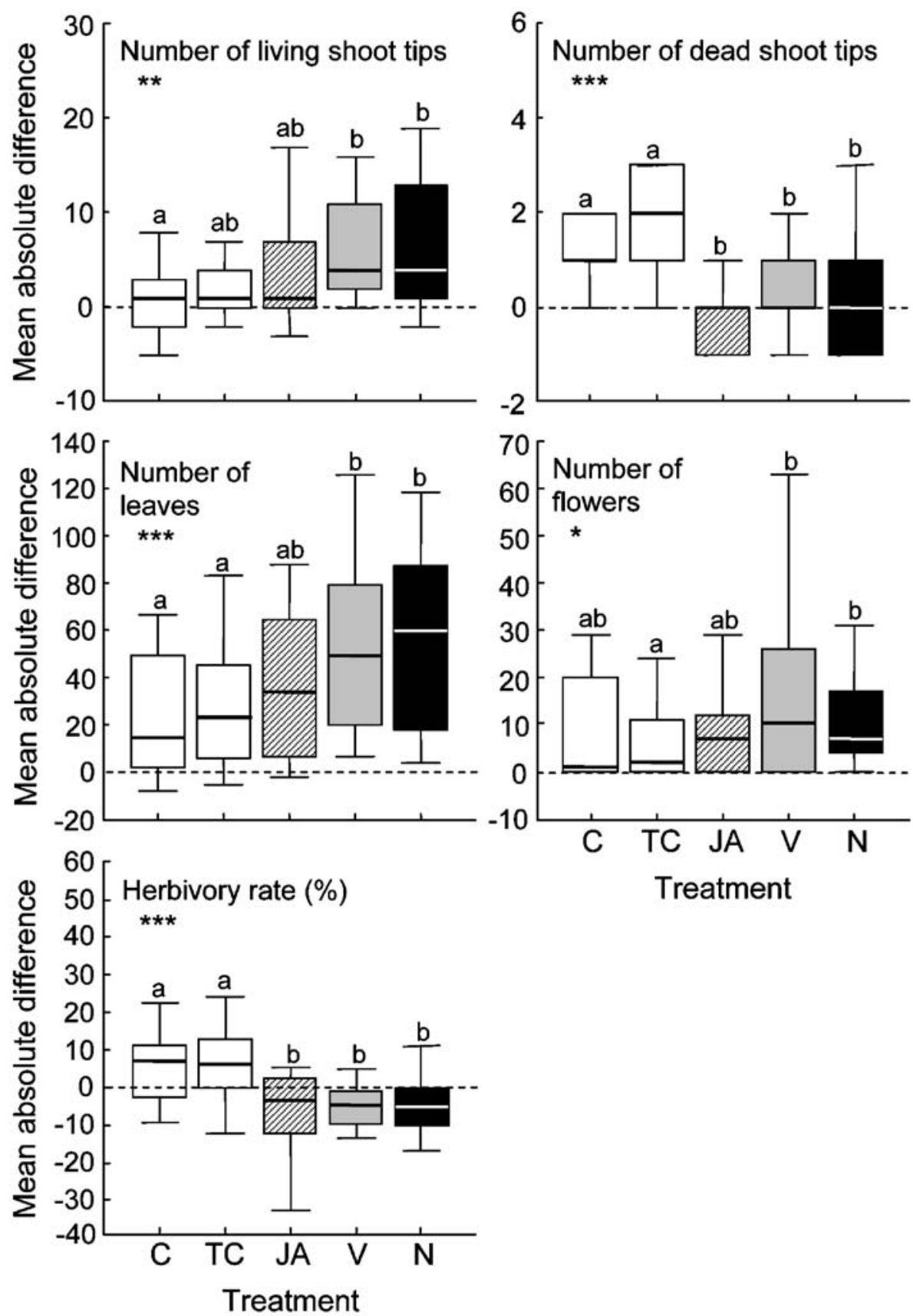

Treatment investigation. A quantitative and qualitative comparison of the VOC blends emitted from herbivore-damaged, volatiletreated, and JA-sprayed lima bean tendrils revealedbesides subtle differences - a pronounced similarity among these three groups with respect to the 13 dominant emitted compounds (Table 2). However, the volatile blends emitted from these three groups were characterized by a high degree of quantitative variation, an observation well known from literature (Kessler and Baldwin 2001; FritscheHoballah et al. 2002; Röse and Tumlinson 2004). The question whether such differences hamper the ability of predators and parasitoids to locate the VOC-emitting plant has been studied intensively under laboratory conditions, where it has been shown that carnivorous arthropods can discriminate even minor differences in volatile blends offered (e.g., changes in the enantiomer ratios; Dicke et al. 1990). A species of curculionid beetles, for example, which also was observed feeding on lima bean in this study (C. Kost, personal observation), in laboratory experiments, used VOCs of slightly induced plants as a host-location cue, yet avoided plants with high induction levels (Heil 2004a). In the field, plants generally show a higher quantitative and qualitative variability of their emitted VOCs than under constant laboratory conditions (Gouinguene et al. 2001; Gouinguene 

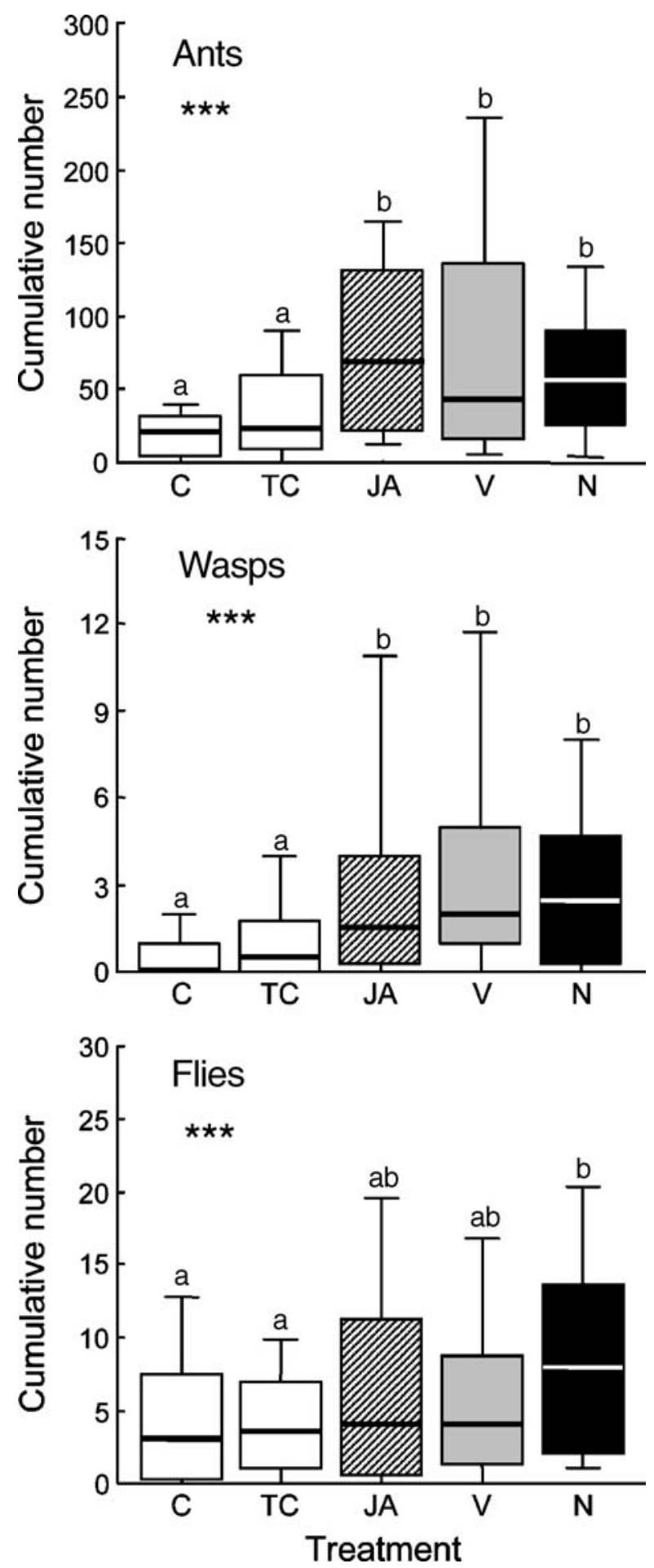

and Turlings 2002; Vallat et al. 2005). Foraging predators should respond to this situation by relaxing the specificity of their search patterns (Dicke et al. 2003). Indeed, field studies on the attractiveness of VOCs suggest that predatory and predacious insects are also attracted to jasmonate-induced plants (Thaler 1999; Kessler and Baldwin 2001), even if the emitted volatiles differ substantially from blends emitted by
Fig. 4 Effect of the five treatments on insect numbers visiting the lima bean. Insects perching on lima bean tendrils that received one of five treatments were counted. Treatments were no treatment $(C)$, treatment with lanolin paste $(T C)$, spraying with jasmonic acid $(J A)$, application of a synthetic volatile blend dissolved in lanolin paste $(V)$, and application of a synthetic mixture of EFN $(N)$. See Table 1 for details. Fourteen censuses were performed within 3 days at two sites (site 1 on day 7 and site 2 on day 18 after the beginning of the experiment). Insect numbers were pooled per counted tendril. Asterisks indicate significant treatment effects (univariate ANOVA; $* P<0.05, * * P<0.01, * * * P<0.001)$, and different letters indicate significant differences among treatments (LSD post hoc test, $P<$ $0.05)$. Sample size was 20 tendril groups

herbivore-damaged plants (Farag and Paré 2002). Moreover, field experiments indicate that the presence of single compounds can be sufficient to attract carnivorous insects (James 2003, 2005; James and Price 2004), which then act as indirect plant defenders (Kessler and Baldwin 2001). Consequently, under our experimental conditions, the VOCs of both JA- and volatile-treated tendrils likely have attracted plant defenders.

Our volatile treatment induced the secretion of EFN (Fig. 2), thus, confirming recent results obtained for the same plant species under laboratory (Choh et al. 2006) and field conditions (Heil and Kost 2006; Kost and Heil 2006). Hence, the tendrils of the volatile group experienced the combined defensive effect of both VOCs and EFN to an extent comparable to the tendrils of the JA group. These two defenses are not only connected by the shared signaling molecule JA (Heil 2004b) but are also airborne VOCs implicated in the induction of EFN secretion within one (Heil and Silva Bueno 2007) or between two conspecific plant individuals (Kost and Heil 2006). Consequently, this physiological linkage precludes an experimental separation of the two indirect defenses.

Treatment Effects on the Plant Tendrils of the JA, the volatile, and the EFN group generally benefited from the respective treatments, as these tendrils suffered less herbivory by leaf-chewing herbivores and bore fewer dead shoot tips than the two control groups (Fig. 3). The picture, however, changes when other fitness-relevant parameters are considered: The numbers of living shoot tips, leaves, and inflorescences differed significantly from the controls only in tendrils treated with VOCs and EFN (Fig. 3). A possible explanation for the weaker effect experienced by the JA-treated tendrils could be that induction with JA incurred allocation costs to the treated tendrils, which were greater than costs imposed by the VOC-induced EFN secretion and absent in EFN-treated tendrils (Heil 2002; Strauss et al. 2002). Beyond eliciting stress-related responses, such as insect and disease resistance, JA is known to be involved in various physiological or morphological changes not necessarily related to resistance 
Fig. 5 Arthropods taxa trapped on sticky traps. Insert Affiliation of trapped taxa to different guilds: predator/entomophaga $(\mathrm{R})$; parasitoid (P); utilization of plant-derived resources including floral or extrafloral nectar, pollen and honeydew $(S)$; frugivore $(F)$; herbivore and flower feeder $(H)$; detrivore including phytosaprophage and zoosaprophage $(D)$; blood-sucking and ectoparasitic $(B)$; and fungivore $(M)$. Arthropod groups were assigned to guilds according to nutritional or functional aspects whenever larval or adult stages feature the respective trait. Multiple affiliations per taxon were allowed. Sample size was two traps per 14 tendril groups

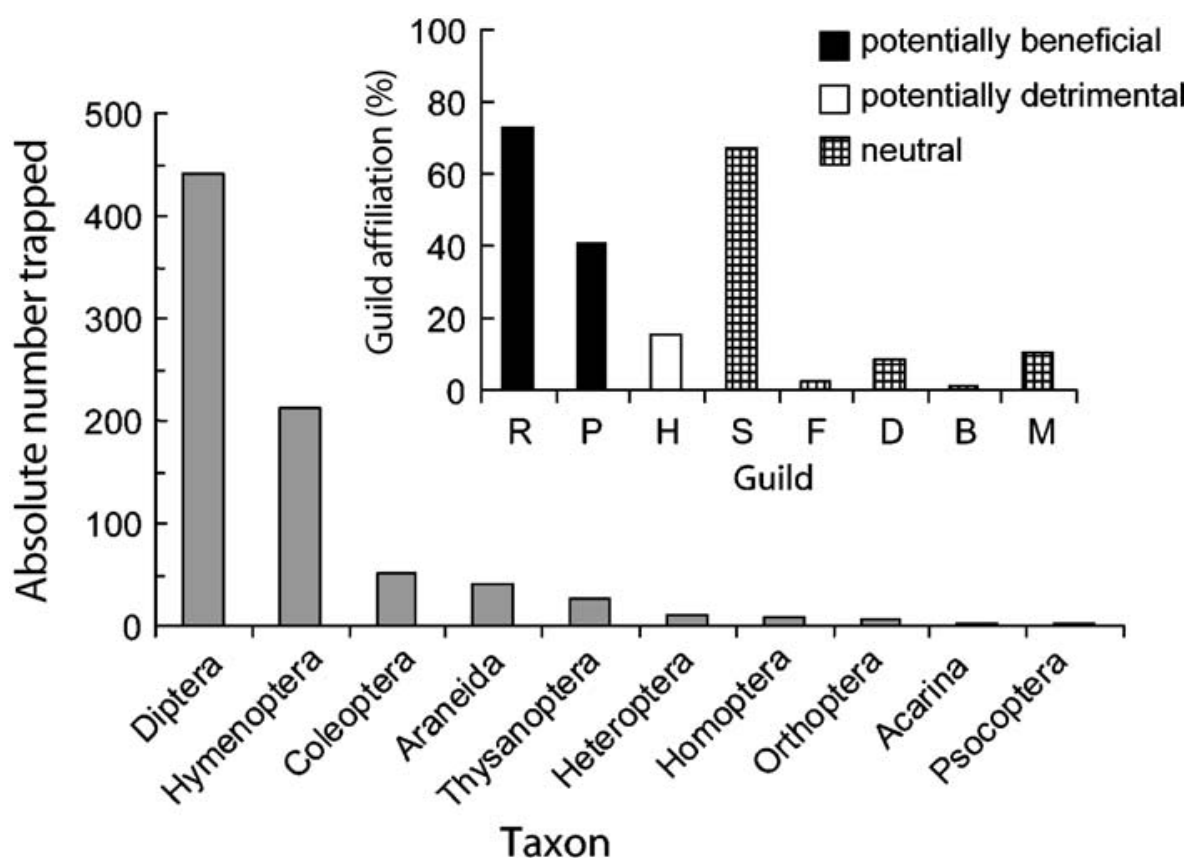

(Creelman and Mullet 1997). Given that these are costly in terms of metabolic resources, the induction of such processes may have affected the measured fitness parameters and could explain the weaker growth and reproductive status of JA-treated tendrils (Agrawal et al. 1999). JA may also directly affect processes such as fruit development and ripening (Creelman and Mullet 1997). An increased seed set of JA-treated plants, therefore, does not necessarily reflect an enhancement of the plant's defense status. Furthermore, external application of JA in elevated concentrations can, in principle, have detrimental effects on a plant and cause chlorosis, necrosis, or abscission of leaves (Husain et al. 1993; Oka et al. 1999; Pilotti et al. 2004). However, no such symptoms of phytotoxicity were observed. In contrast, the leaves of JA-treated tendrils looked even healthier than those of both control tendrils.

Additionally, JA application may have induced putative direct defenses (Halitschke and Baldwin 2004). However, no such alternative defense strategy has yet been described for lima bean. In its close relative, P. vulgaris, EnglishLoeb and Karban (1991) did not find evidence for induced direct resistance to spider mites. However, the protective effect of a direct defense, which in our long-term experiment could have been induced after JA application, cannot be excluded. In this case, the direct defense did not significantly contribute to plant protection because tendrils with increased amounts of EFN only (EFN group) or volatiles and EFN combined (volatile group) performed better than tendrils with volatiles, EFN, and the putative direct defense (JA group; Fig. 3).
The development of the fitness-relevant plant parameters measured in the JA-treated group and the two controls confirmed a preceding study (Heil 2004b). In both studies, JA treatment increased the number of newly produced leaves and decreased both the number of dead shoot tips, as well as the herbivory rate. The induction of these two indirect defenses was shown to benefit lima bean plants in two independent studies performed in two consecutive years. By applying synthetic VOCs and EFN externally, we could trace the observed effects back to these two kinds of defensive metabolites and corroborate the importance of EFN secretion and VOC emission for lima bean defense in nature.

Treatment Effects on the Insect Community Ants were by far the dominant insect group observed on experimental tendrils, and they were significantly attracted to tendrils that experienced the JA, volatile, and EFN treatment (Fig. 4). Although chemical cues are generally important for ants (Vander Meer et al. 1998; Keeling et al. 2004), little is known about whether plant-derived volatiles also influence ant behavior. Some reports are available on the role of yet unidentified plant chemicals that orient ants to their host plant (Fiala and Maschwitz 1990; Agrawal and DubinThaler 1999; Djieto-Lordon and Dejean 1999a,b) or facilitate within-host plant patrolling behavior (Brouat et al. 2000). In lima bean, herbivory induces both VOC emission and EFN secretion (Heil 2004b). Ants could use herbivore-induced volatiles as long-distance cues to detect patches of increased availability of EFN, which simultaneously are characterized by the increased presence of herbivores (i.e., potential prey). However, preliminary 
experiments with Camponotus novogranadensis, one of the three dominant ant species that visit lima bean at the two study sites (Kost and Heil 2005) did not support this hypothesis. Given the choice in a Y-olfactometer, workers of $C$. novogranadensis neither preferred lanolin paste that contained volatiles over pure lanolin paste. They also did not discriminate between JA-induced vs water-sprayed control plants. However, in previous trials they significantly chose an arm with mashed banana (C. Kost, unpublished data). More experiments of this kind will clarify the role of plant volatiles in ant foraging behavior.

In contrast to VOCs, EFN is a known attractant to ants (Koptur 1992) that has been reported to translate into enhanced plant protection in the vast majority of studies (for review, see Bentley 1977; Koptur 1992; Heil and McKey 2003; Oliveira and Freitas 2004), although some studies did not detect a defensive effect (O'Dowd and Catchpole 1983; Boecklen 1984; Becerra and Venable 1989; Rashbrook et al. 1992).

Also, wasps were more attracted to the tendrils of the JA, volatile, and EFN groups than to the control tendrils, yet in much smaller numbers than ants. The majority of wasps trapped on experimental tendrils belonged to predacious or parasitoid families (Table S1). These observations suggest that not only ants but also wasps likely contributed to the protection of the treated tendrils. Because of the intrinsic physiological linkage between volatiles and EFN, however, it remains unclear which indirect defense was mainly responsible for wasp attraction. As the emission of VOCs from a lima bean plant is correlated with its amount of EFN secreted, it appears reasonable to assume that wasps may have used VOCs as long-distance cues to detect patches with an increased herbivore density and/or EFN availability.

Comprehensive evidence for the volatile-mediated attraction of wasp is available from many laboratory-based studies (e.g., Turlings et al. 1990; Takabayashi et al. 1995; $\mathrm{Du}$ et al. 1996), yet relatively few field studies. Among them, James (2005) identified methyl salicylate as an attractant for parasitic wasps such as Encyrtidae and Mymaridae. Furthermore, braconid wasps were attracted to (3Z)-hexen-1-yl acetate and (Z)-jasmone (James 2005). These three compounds were also constituents of the synthetic volatile blend used in our study, and the abovementioned parasitic wasps were also trapped on our experimental tendrils. In another study, DMNT (another constituent of the lima bean's induced VOC blend) emitted from molasses grass (Melinis minutiflora) significantly attracted parasitoid wasps in the Y-tube olfactometer and was likely involved in increasing the parasitation rate of stem-borer larvae that were feeding on nearby growing maize plants (Khan et al. 1997). Wasps feeding on EFN have been reported for several different plant species (for review, see Koptur 1992), yet so far, only one study has also demonstrated a fitness-benefit for the EFN-secreting plant (Cuautle and Rico-Gray 2003). A more detailed analysis of the attractive effects of VOCs and EFN on wasps is required, in which single blend constituents should be tested under field conditions.

Flies responded differently to tendril treatment than ants and wasps. They were only significantly attracted to tendrils of the nectar group (Fig. 4), suggesting that flies were more attracted to synthetic EFN than to airborne VOCs. The community of trapped Diptera covered a diverse spectrum of feeding habits ranging from predacious or parasitoid over herbivorous to detritus- or fungi-feeding (Table S1). This heterogeneous composition complicates a clear functional assignment of the caught flies. In most cases, the offered EFN seems to have been exploited by the flies as an additional food source rather than having contributed to a large extent to plant protection. In this case, the consumption of EFN without providing plant protection would cause ecological costs because the EFNproducing plant would be less protected against herbivores (Heil 2002; Heil et al. 2004).

In summary, ecological studies on the benefit of indirect defenses have generally focused on the protective role of a single defensive trait. While this simplification is easy to understand from the viewpoint of experimental feasibility, such univariate approaches may be inappropriate because they do not appreciate the complex interplay of several plant defenses that can co-occur within one plant species (Duffey and Stout 1996). This study takes a first step in this direction.

The mere application of synthetic EFN (nectar group) resulted in a fitness benefit that was always stronger or quantitatively similar to that experienced by tendrils of the JA and VOC treatments (Fig. 3). Moreover, the number of ants observed on the experimental tendrils (i.e., typical EFN feeders but less known to respond to VOCs) overwhelmingly exceeded the number of all other arthropod groups (Fig. 4). These observations suggest that, under our experimental conditions, the presence of EFN was more important for plant defense than was the VOC-mediated attraction of arthropods.

However, the inducing effect of VOCs on EFN impeded an experimental separation of VOCs and EFN and, thus, the exclusion of an attractive effect of airborne VOCs on flying or crawling arthropods. This finding underlines the necessity of studying different plant traits such as indirect defenses simultaneously in their ecological context. Studying them separately may provide a distorted picture of their true function and likely cause an under- or overestimation of their true effect.

This issue needs to be addressed in future studies, which should focus especially on the role of volatiles and EFN for 
short- and long-distance attraction of herbivores and plant defenders. Several of the arthropod taxa that were identified in this study could serve as possible targets for such analyses. Further laboratory and field-based experimentation is needed to study whether inductive situations exist, in which either the volatile emission or the EFN secretion is differentially up- or down-regulated or if both defenses always respond similarly to herbivore attack.

Acknowledgment We thank W. Boland for the use of all the facilities of the Department of Bioorganic Chemistry, and S. Adolph and M. Mekem Sonwa for the technical advice on organic synthesis. This manuscript benefited greatly from constructive comments of $\mathrm{S}$. Schmidt, C. C. von Dahl, E. Wheeler, A. Giri, and M. Hartl. Financial support by the German Research Foundation (DFG grant He 3169/2$1,2)$ and the Max-Planck-Society is gratefully acknowledged.

\section{References}

Agrawal, A. A., and Dubin-Thaler, B. J. 1999. Induced responses to herbivory in the Neotropical ant-plant association between Azteca ants and Cecropia trees: response of ants to potential inducing cues. Behav. Ecol. Sociobiol 45:47-54.

Agrawal, A. A., Strauss, S. Y., and Stout, M. J. 1999. Costs of induced responses and tolerance to herbivory in male and female fitness components of wild radish. Evolution 53:1093-1104.

ARIMURA, G. I., Kost, C., and Boland, W. 2005. Herbivore-induced, indirect plant defenses. Biochim. Biophys. Acta, Lipid Lipid Metab. 1734:91-111.

ARNETT, R. H. 2000. American Insects-A Handbook of the Insects of America North of Mexico. CRC Press, Boca Raton.

BECERRA, J. X. I., and VenABLE, D. L. 1989. Extrafloral nectaries: a defense against ant-Homoptera mutualisms? Oikos 55:276-280.

Bentley, B. L. 1977. Extrafloral nectaries and protection by pugnacious bodyguards. Annu. Rev. Ecol. Syst 8:407-427.

BOECKLEN, W. J. 1984. The role of extrafloral nectaries in the herbivore defense of Cassia fasciculata. Ecol. Entomol 9:243-249.

Brouat, C., Mckey, D., Bessiere, J. M., Pascal, L., and HossaertMCKEY, M. 2000. Leaf volatile compounds and the distribution of ant patrolling in an ant-plant protection mutualism: preliminary results on Leonardoxa (Fabaceae: Caesalpinioideae) and Petalomyrmex (Formicidae: Formicinae). Acta Oecol 21:349-357.

Choh, Y., KugimiYa, S., and Takabayashi, J. 2006. Induced production of extrafloral nectar in intact lima bean plants in response to volatiles from spider mite-infested conspecific plants as a possible indirect defense against spider mites. Oecologia 147:455-460.

Creelman, R. A., and Mullet, J. E. 1997. Biosynthesis and action of jasmonates in plants. Annu. Rev. Plant Physiol. Plant. Mol. Biol 48:355-381.

Cuautle, M., and ICO-Gray, V. 2003. The effect of wasps and ants on the reproductive success of the extrafloral nectaried plant Turnera ulmifolia (Turneraceae). Funct. Ecol 17:417-423.

Daly, H. V., Doyen, J. T., and Purcell, A. H. 1998. Introduction to Insect Biology and Diversity. Oxford University Press, Oxford.

Dicke, M., De Boer, J. G., Hofte, M., and ocha-Granados, M. C. 2003. Mixed blends of herbivore-induced plant volatiles and foraging success of carnivorous arthropods. Oikos 101:38-48.

Dicke, M., Vanbeek, T. A., Posthumus, M. A., Bendom, N., Vanbokhoven, H., and Degroot, A. E. 1990. Isolation and identification of volatile kairomone that affects acarine predator- prey interactions - involvement of host plant in its production. $J$. Chem. Ecol 16:381-396.

DJieto-Lordon, C., and DeJEAn, A. 1999a. Innate attraction supplants experience during host selection in an obligate plantant. Behav. Process 46:181-187.

Difeto-Lordon, C., and DeJEAn, A. 1999b. Tropical arboreal ant mosaics: innate attraction and imprinting determine nest site selection in dominant ants. Behav. Ecol. Sociobiol 45:219-225.

Donath, J., and Boland, W. 1995. Biosynthesis of acyclic homoterpenes: enzyme selectivity and absolute configuration of the nerolidol precursor. Phytochemistry 39:785-790.

Du, Y. J., PopPy, G. M., and Powell, W. 1996. Relative importance of semiochemicals from first and second trophic levels in host foraging behavior of Aphidius ervi. J. Chem. Ecol 22:1591-1605.

DufFeY, S. S., and Stout, M. J. 1996. Antinutritive and toxic components of plant defense against insects. Arch. Insect Biochem. Physiol 32:3-37.

ENGLiSh-LOEB, G. M., and KARBAN, R. 1991. Consequences of mite feeding injury to beans on the fecundity and survivorship of the two-spotted spider mite (Acari: Tetranychidae). Exp. Appl. Acarol 11:125-136.

FARAG, M. A., and PARÉ, P. W. 2002. $\mathrm{C}_{6}$-Green leaf volatiles trigger local and systemic VOC emissions in tomato. Phytochemistry 61:545-554.

Fiala, B., and Maschwitz, U. 1990. Studies on the Southeast Asian ant-plant association Crematogaster borneensis/Macaranga: adaptations of the ant partner. Insectes Soc 37:212-231.

Fritsche-Hoballah, M. E., TAMO, C., and TurlingS, T. C. J. 2002. Differential attractiveness of induced odors emitted by eight maize varieties for the parasitoid Cotesia marginiventris: is quality or quantity important? J. Chem. Ecol 28:951-968.

Galetto, L., and Bernardello, L. M. 1992. Extrafloral nectaries that attract ants in Bromeliaceae: structure and nectar composition. Can. J. Bot 70:1101-1106.

Gouinguene, S., Degen, T., and Turlings, T. C. J. 2001. Variability in herbivore-induced odour emissions among maize cultivars and their wild ancestors (teosinte). Chemoecology 11:9-16.

Gouinguene, S. P., and Turlings, T. C. J. 2002. The effects of abiotic factors on induced volatile emissions in corn plants. Plant Phys 129:1296-1307.

HALitschKe, R., and BALDWIN, I. T. 2004. Jasmonates and related compounds in plant-insect interactions. J. Plant Growth Regul $23: 238-245$.

HeIL, M. 2002. Ecological costs of induced resistance. Curr. Opin. Plant Biol 5:345-350.

HeIL, M. 2004a. Direct defense or ecological costs: responses of herbivorous beetles to volatiles released by wild lima bean. $J$. Chem. Ecol 30:1289-1295.

HeIL, M. 2004b. Induction of two indirect defenses benefits lima bean (Phaseolus lunatus, Fabaceae) in nature. J. Ecol 92:527-536.

Heil, M., Fiala, B., Baumann, B., and Linsenmair, K. E. 2000. Temporal, spatial and biotic variations in extrafloral nectar secretion by Macaranga tanarius. Funct. Ecol 14:749-757.

Heil, M., Hilpert, A., KrÜGer, R., and Linsenmair, K. E. 2004. Competition among visitors to extrafloral nectaries as a source of ecological costs of an indirect defense. J. Trop. Ecol 20:201-208.

Heil, M., Koch, T., Hilpert, A., Fiala, B., Boland, W., and LINSENMAIR, K. E. 2001. Extrafloral nectar production of the antassociated plant, Macaranga tanarius, is an induced, indirect, defensive response elicited by jasmonic acid. Proc. Natl. Acad. Sci. USA 98:1083-1088.

HeIL, M., and Kost, C. 2006. Priming of indirect defenses. Ecol. Lett 9:813-817.

HeIL, M., and McKey, D. 2003. Protective ant-plant interactions as model systems in ecological and evolutionary research. Аnnu. Rev. Ecol. Evol. Syst 34:425-453. 
HeIL, M., and Silva Bueno, J. C. 2007. Within-plant signaling by volatiles leads to induction and priming of an indirect plant defense in nature. Proc. Natl. Acad. Sci. USA 104:5467-5472.

Honomichl, K., BellmanN, H., JaCoBS, W., and ENNER, M. 1996. Biologie und Ökologie der Insekten. Gustav Fischer Verlag, Stuttgart.

Husain, A., Ahmad, A., and Agrawal, P. K. 1993. (-)-Jasmonic acid, a phytotoxic substance from Botryodiplodia theobromaecharacterization by NMR spectroscopic methods. J. Nat. Prod 56:2008-2011.

JAMES, D. G. 2003. Field evaluation of herbivore-induced plant volatiles as attractants for beneficial insects: methyl salicylate and the green lacewing, Chrysopa nigricornis. J. Chem. Ecol 29:1601-1609.

JAMES, D. G. 2005. Further field evaluation of synthetic herbivoreinduced plant volatiles as attractants for beneficial insects. $J$. Chem. Ecol 31:481-495.

JAMES, D. G., and PRICE, T. S. 2004. Field-testing of methyl salicylate for recruitment and retention of beneficial insects in grapes and hops. J. Chem. Ecol 30:1613-1628.

KARBAN, R., and BALDWIN, I. T. 1997. Induced Responses to Herbivory. University of Chicago Press, Chicago.

Keeling, C. I., Plettner, E., and Slessor, K. N. 2004. Hymenopteran semiochemicals. Top. Curr. Chem 239:133-177.

Kelsey, L. P. 1969. A revision of the Scenopinidae (Diptera) of the world. Bull. US Natl. Mus 277:1-336.

Kelsey, L. P. 1981. New Scenopinidae (Diptera) from the Palearctic. Folia Entomol. Hung 2:85-93.

Kessler, A., and BALDWIN, I. 2001. Defensive function of herbivoreinduced plant volatile emissions in nature. Science 291:2141-2144.

Khan, Z. R., Ampong-Nyarko, K., Chiliswa, P., Hassanali, A., Kimani, S., Lwande, W., Overholt, W. A., Pickett, J. A., Smart, L. E., Wadhams, L. J., and Woodcock, C. M. 1997. Intercropping increases parasitism of pests. Nature 388:631-632.

Koch, T., Krumm, T., Jung, V., Engelberth, J., and Boland, W. 1999. Differential induction of plant volatile biosynthesis in the lima bean by early and late intermediates of the octadecanoidsignaling pathway. Plant Physiol 121:153-162.

KOPTUR, S. 1992. Extrafloral nectary-mediated interactions between insects and plants, pp. 81-129, in E. Bernays (ed.). Insect-Plant InteractionsCRC Press, Boca Raton.

Kost, C., and HeIL, M. 2005. Increased availability of extrafloral nectar reduces herbivory in lima beans (Phaseolus lunatus, Fabaceae). Basic Appl. Ecol 6:237-248.

Kost, C., and HeIL, M. 2006. Herbivore-induced plant volatiles induce an indirect defense in neighbouring plants. J. Ecol 94:619-628.

MAtile, L. 1997. Phylogeny and evolution of the larval diet in the Sciaroidea (Diptera, Bibionomorpha) since the Mesozoic. Mem. Mus. Natl. Hist. Nat 173:273-303.

Munzel, U., and Hothorn, L. A. 2001. A unified approach to simultaneous rank test procedures in the unbalanced one-way layout. Biometrical J 43:553-569.

NOYES, J. S. 2003. Universal Chalcidoidea Database. World Wide Web Electronic Publication. http://www.nhm.ac.uk/entomology/ chalcidoids/index.html. Cited 05 Sep. 2003. The Natural History Museum, London, UK.
O'Dowd, D. J., and CATChPole, E. A. 1983. Ants and extrafloral nectaries: no evidence for plant protection in Helichrysum sppant interactions. Oecologia 59:191-200.

OKA, Y., Cohen, Y., and SpIEgel, Y. 1999. Local and systemic induced resistance to the root-knot nematode in tomato by DLbeta-amino-n-butyric acid. Phytopathology 89:1138-1143.

Oliveira, P. S., and Freitas, A. V. L. 2004. Ant-plant-herbivore interactions in the neotropical cerrado savanna. Naturwissenschaften 91:557-570.

PARÉ, P. W., and Tumlinson, J. H. 1997. De novo biosynthesis of volatiles induced by insect herbivory in cotton plants. Plant Physiol 114:1161-1167.

Pattenden, G., and WeEdon, B. L. L. 1968. Carotenoids and related compounds. Part XVIII. Synthesis of cis-and di-cis-polyenes by reactions of the Wittig type. J. Chem. Soc. C 16:1984-1997.

Pilotti, M., Festa, S., GerVASI, E., and CopPOLA, F. 2004. Biological assays to study induction of resistance in Platanus $\times$ acerifolia to Ceratocystis fimbriata. J. Plant Pathol 86:71-83.

Price, P. W., Bouton, C. E., Gross, P., Mcpheron, B. A., ThOMPSON, J. N., and WeIs, A. E. 1980. Interactions among 3 trophic levels - influence of plants on interactions between insect herbivores and natural enemies. Annu. Rev. Ecol. Syst 11:41-65.

RashbrooK, V. K., COMPTON, S. G., and LAWTON, J. H. 1992. Antherbivore interactions: reasons for the absence of benefits to a fern with foliar nectaries. Ecology 73:2167-2174.

RöSE, U. S. R., and TUMLinson, J. H. 2004. Volatiles released from cotton plants in response to Helicoverpa zea feeding damage on cotton flower buds. Planta 218:824-832.

RUfFNER, G. A., and CLARK, W. D. 1986. Extrafloral nectar of Ferocactus acanthodes (Cactaceae): composition and its importance to ants. Am. J. Bot 73:185-189.

Schaefer, M., Bohlken, H., eichstein, H., SATtler, K., SchmidT, E., SICK, F., and TISCHLER, W. 1994. Brohmer-Fauna von Deutschland. Quelle und Meyer Bestimmungsbücher, Heidelberg.

STRÄSSNE, M. 1999. Klimadiagramme der Erde-Teil 2: Asien, Lateinamerika, Afrika, Australien und Ozeanien, Polarländer. Dortmunder Vertrieb für Bau-und Planungsliteratur, Dortmund.

Strauss, S. Y., udgers, J. A., LaU, J. A., and Irwin, R. E. 2002. Direct and ecological costs of resistance to herbivory. Trends Ecol. Evol 17:278-285.

TaKabayashi, J., TaKahashi, S., Dicke, M., and Posthumus, M. A. 1995. Developmental stage of herbivore Pseudaletia separata affects production of herbivore-induced synomone by corn plants. J. Chem. Ecol 21:273-287.

THALER, J. S. 1999. Jasmonate-inducible plant defenses cause increased parasitism of herbivores. Nature 399:686-688.

Turlings, T. C. J., Tumlinson, J. H., and Lewis, W. J. 1990. Exploitation of herbivore-induced plant odors by host-seeking parasitic wasps. Science 250:1251-1253.

Vallat, A., Gu, H. N., and DoRn, S. 2005. How rainfall, relative humidity and temperature influence volatile emissions from apple trees in situ. Phytochemistry 66:1540-1550.

Vander Meer, R., Breed, M., Espelie, K., and Winston, M. 1998. Pheromone Communication in Social Insects: Ants, Wasps, Bees, and Termites. Westview Press, Boulder. 